\title{
Determination of aflatoxin B1 in cosmetics containing botanical ingredients by enzyme linked immunosorbent assay
}

\author{
Ișıl Gazioğlu (i) \\ Department of Analytical Chemistry, Bezmialem Vakif University, Faculty of Pharmacy, 34093, İstanbul, Turkey
}

ORCID ID of the author: I.G. 0000-0002-3283-1824.

Cite this article as: Gazioğlu I (2019). Determination of aflatoxin B1 in cosmetics containing botanical ingredients by enzyme linked immunosorbent assay. Istanbul J Pharm 49 (2): 88-91.

\begin{abstract}
Botanicals are widely used in cosmetic products due to their rich chemical compositions. There are numerous factors that affect the chemical profile of botanical content including growing, harvesting, drying and storage conditions. The reliability of a cosmetic product containing botanical ingredients is closely related to the quality control processes of the raw material. Aflatoxins can be transmitted to the botanicals at every stage of the production. The purpose of this study is to evaluate the ELISA method for the determination of aflatoxins in 20 personal care products containing plant extracts and/or oil. In this study, aflatoxin B1 (AFB1) was not detected in one of the samples containing chamomile extract, rose, shea \& orange, and cocoa butter. Of the tested samples, $35 \%$ exceeded the legal limits of AFB1. The highest level was determined in sample containing coconut butter (15.13 ppb). These results show that raw materials of cosmetic products should be regularly and effectively controlled.

Keywords: Aspergillus flavus, aflatoxin B1, cosmetics, ELISA, mycotoxin
\end{abstract}

\section{INTRODUCTION}

Aflatoxins are considered one of the major mycotoxins because of their toxicological effects on human health. Aspergillus strains are aflatoxin producers (Stroka et al. 1999). These contain A. flavus, A. parasiticus, A. nomius, A. pseudotamarii, and A. bombycis (Wilson et al. 2002; Gnonlonfin et al. 2013). Although aflatoxins are soluble in methanol, chloroform and acetone, they are insoluble in water and petroleum ether. When dry, they are heat resistant to their melting point (Hacibekiroglu and Kolak 2013). Diseases caused by aflatoxin are called aflatoxicosis. Exposure to high doses of aflatoxin (over $6000 \mathrm{mg}$ ) may induce acute toxicity with fatal effects (Groopman and Kensler 1999). Prolonged exposure to aflatoxin has been shown to be associated with liver cancer.

Raw plant materials are frequently contaminated with aflatoxin produced by fungi generated from the soil. Contamination of plant materials can also occur pre- or post-harvest during processing, preparation or in storage (Trucksess and Scott 2008). Plant extracts are usually prepared to modify any possible benefits that the plant may have. Some of these extracts are standardized to protect a known concentration of the active compound and to ensure that the concentration of the compound will be stable (Draelos and Thaman 2006), and they are used for different purposes. These properties of cosmetics containing natural products were made more effective by increasing the reliability and biodiversity of raw materials. With the improvement of the basic methods and the development of new technologies, new sources for pure raw material have been found. Botanicals have been an important part of cosmetics. Botanical oils have been used to soften skin and mask body odour, and body sprays have been made from mixtures of essential oils such as chamomile, rose, and cedar, merged in oils of olive, sesame, or almond (Davis 1990; Wagemaker et al. 2013). Botanicals are not just for perfumes and colour; many natural product extracts also have been used in various pharmaceutical drugs (Buchbinder et al. 1999; Draelos and Thaman 2006; Boga et al. 2011). 
Biologically active compounds from natural sources may provide health benefits as well as cosmetic benefits (dal Belo et al. 2009). Today, botanical extracts can be found in everything from hand cream to lipstick (Frauen et al. 2002; Gianeti et al. 2013; Beiki et al. 2018). Botanical extracts/oils may come in many forms (Marks 1997). However, the addition of botanical extracts to various cosmetic products requires the analysis of mycotoxin toxicity, especially aflatoxin (Voss 2007). Maximum levels set by the European community for most food products are 2 ppb aflatoxin B1. However; maximum levels have not been specified for botanical oils or cosmetic oils. Aflatoxins are analyzed in major foods but they are not analysed in botanical raw materials (Mahoney and Molyneux 1998).

In this study, 20 hand lotions containing botanical extracts and/or oils were analyzed for aflatoxin B1 (AFB1) (Figure 1) contamination by using ELISA due to its simplicity, sensitivity and adaptability. Enzyme-linked immunosorbent assay is the most commonly applied test to detect aflatoxins.

\section{MATERIAL AND METHODS}

\section{Reagents}

ELISA was performed using Ridascreen Fast Aflatoxin (Art No: R5202) (R-Biopharm AG, Darmstadt, Germany). AFB1 standard came with a ready-to-use ELISA kit. All solvents were of analytical grade.

\section{Samples}

Twenty hand cream samples containing botanical ingredients were randomly purchased from different local markets and supermarkets in Istanbul, Turkey. All samples were kept in their containers and stored at room temperature until sample preparation, and then stored at $+4{ }^{\circ} \mathrm{C}$ in the dark until the analysis. Brands were not recorded.

\section{Sample Preparation}

A sample of one gram was placed into falcon tubes and 10 $\mathrm{mL}$ of methanol (70\%) was added. After shaking vigorously for 2 minutes with a vortex, the extract was filtered through a syringe filter. A measured quantity of $1 \mathrm{~mL}$ of the filtrate was diluted to $1 \mathrm{~mL}$ with distilled water; $50 \mu \mathrm{L}$ of the diluted filtrate was used per well in the test. All reagents and standards were brought to room temperature $\left(20-25^{\circ} \mathrm{C}\right)$ before use.

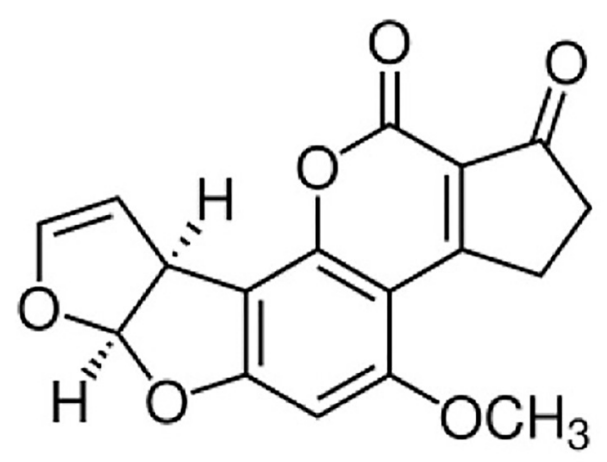

Figure 1. AFB1.

\section{Procedure}

$50 \mu \mathrm{L}$ of the standards $(0,1,5,10,20,50 \mu \mathrm{g} / \mathrm{kg})$ were transferred into 5 wells of the first strip and $50 \mu \mathrm{L}$ of the samples were transferred into wells of the second strip of the ELISA plate.

First, the enzyme conjugate solution $(50 \mu \mathrm{L})$ and then the aflatoxin antibody solution $(50 \mu \mathrm{L})$ were added to the plate. After mixing slowly by shaking the plate manually and incubating for 10 minutes at room temperature, the liquid was dumped out of the wells. The wells were filled with PBS-tween buffer (250 $\mathrm{\mu L}$ per well). The wells were emptied again removing all remaining liquid. The washing step was repeated two more times. $100 \mu \mathrm{L}$ of substrate/chromogen was added to each well and the plate was gently mixed manually by shaking and then incubated for 5 minutes at room temperature in the dark. Finally, $100 \mu \mathrm{L}$ of a stop solution (10\% sulphuric acid) was added to each well and the plate was mixed gently by shaking manually The absorbance was measured at $450 \mathrm{~nm}$ with an ELISA Reader (Biotek" Synergy H1 Hybrid Reader) and evaluated with RIDA'SOFT Win (Art. No. Z9999) software, specialized to the Ridascreen enzyme immunoassays.

\section{Recovery}

Analyses were performed with the R-Biopharm ELISA system (Darmstadt, Germany), which is accredited by DQS (the German Accreditation body) to ISO 9001, 13485 and 17025. For the recovery study, the AFB1 standard solution $(100 \mu \mathrm{g} / \mathrm{kg}$ ) was prepared in methanol-water (30:70) and each sample containing raw botanical cosmetics was spiked with three different concentrations of AFB1 $(1.0,2.5,5.0 \mu \mathrm{g} / \mathrm{kg})$. The recovery percentages were calculated by the following equation:

Recovery $(\%)=$ (Spiked amount of standard / Actual amount added) $\times 100$

\section{RESULTS AND DISCUSSION}

Due to its simplicity, sensitivity and adaptability, the ELISA assay is the most commonly used method to detect aflatoxins (Biermann and Terplan 1980; Biermann and Terplan 1982; Danier et al. 1994). To detect the aflatoxins, the direct competitive ELISA method is used. This method detects and quantifies an antigen (aflatoxin) in a sample by using an enzyme labelled toxin and antibodies specific to the antigen. In this assay, the absorbance measurement of the blue product is made at $450 \mathrm{~nm}$ by the ELISA reader. The absorbance is inversely proportional to the aflatoxin concentration in the sample; the lower the absorbance shows, the higher the aflatoxin concentration (R-Biopharm 2006).

A cosmetic product made from plant material is a cosmetic product obtained from the entire plant or specific parts of the plant (roots, flowers, fruits, leaves or seeds). In considering the reliability of botanical ingredients used in personal care products, it is important to pay attention to the specific botanical material, the amount of the botanical in the raw material and final product, and the route of exposure. Personal care product manufacturers are required by law to sufficiently prove the reliability of the products containing botanical ingredients. Of the various botanical ingredients used in making cosmetics, aflatoxin is one of the most hazardous substances to controls. 
Samples of each cosmetic containing botanical ingredients were obtained from different local markets. The botanics in hand creams were chamomile (five samples), green tea (three samples), coconut (three samples), rose (two samples), shea \& orange (one sample), lavender (one sample), lemon \& sage (one sample), avocado (one sample), lilly pilly fruit. (one sample), jojoba oil (one sample), and cocoa butter (one sample). In order to see the recovery, before the sample analysis, the purchased raw botanicals were triply spiked with AFB1 at low, middle, and high levels (1.0, 2.5, and 5.0 ppb, respectively). The spiked samples were then subjected to a clean-up procedure and analyzed for recovery by ELISA detection. The recovery

\section{Table 1. Recovery percentage of spiked sample containing raw botanical cosmetics. LOD is $1.0 \mu \mathrm{g} /$ kg for AFB1, as indicated by R-Biopharm test kit manuals}

\begin{tabular}{|c|c|c|}
\hline $\begin{array}{l}\text { Sample group } \\
\text { (containing botanical } \\
\text { cosmetic) }\end{array}$ & $\begin{array}{c}\text { AFB1 spike level } \\
(\mu \mathrm{g} / \mathrm{kg})\end{array}$ & Recovery (\%) \\
\hline \multirow[t]{3}{*}{ Camomile } & 1.0 & 94.3 \\
\hline & 2.5 & 82.8 \\
\hline & 5.0 & 102.3 \\
\hline \multirow[t]{3}{*}{ Green tea } & 1.0 & 100.2 \\
\hline & 2.5 & 88.1 \\
\hline & 5.0 & 102.2 \\
\hline \multirow[t]{3}{*}{ Coconut } & 1.0 & 94.4 \\
\hline & 2.5 & 89.9 \\
\hline & 5.0 & 99.5 \\
\hline \multirow[t]{3}{*}{ Rose } & 1.0 & 99.5 \\
\hline & 2.5 & 93.2 \\
\hline & 5.0 & 91.2 \\
\hline \multirow[t]{3}{*}{ Shea butter \& orange } & 1.0 & 100.2 \\
\hline & 2.5 & 95.5 \\
\hline & 5.0 & 89.1 \\
\hline \multirow[t]{3}{*}{ Lavender } & 1.0 & 99.5 \\
\hline & 2.5 & 97.0 \\
\hline & 5.0 & 89.3 \\
\hline \multirow[t]{3}{*}{ Lemon \& Sage } & 1.0 & 98.5 \\
\hline & 2.5 & 89.2 \\
\hline & 5.0 & 76.5 \\
\hline \multirow[t]{3}{*}{ Avocado } & 1.0 & 96.7 \\
\hline & 2.5 & 91.0 \\
\hline & 5.0 & 83.1 \\
\hline \multirow[t]{3}{*}{ Lilly pilly fruit } & 1.0 & 97.2 \\
\hline & 2.5 & 92.4 \\
\hline & 5.0 & 81.9 \\
\hline \multirow[t]{3}{*}{ Jojoba oil } & 1.0 & 98.5 \\
\hline & 2.5 & 92.9 \\
\hline & 5.0 & 80.6 \\
\hline \multirow[t]{3}{*}{ Cocoa butter } & 1.0 & 99.9 \\
\hline & 2.5 & 94.1 \\
\hline & 5.0 & 78.8 \\
\hline
\end{tabular}

rate of AFB1 is between $76.5 \%$ and $102.3 \%$ (Table 1), which shows good method performance. The sample containing raw botanical cosmetics was also spiked with AFB1 to ensure that the oils were not contaminated with aflatoxin prior to the procedure. Aflatoxin standards with different concentrations were read with the ELISA Reader at $450 \mathrm{~nm}$ (R-Biopharm 2006). Results were evaluated with RIDAWIN in Software and a calibration curve was generated. Standard, sample concentrations, and calculated ppb are shown in supplementary data, and the number of the samples with AFB1 in the range are shown in Table 2.

Of the tested samples, 35\% exceeded legal limits of AFB1. This study shows that the highest AFB1 levels were in three of the chamomile samples, all of the green tea samples and one of the coconut samples. According to the results, the highest AFB1 level was found to be in the sample containing coconut butter (15.13 ppb). Similar to our results, in a previous study, the chloroform extracts of the coconut samples showed that 5 out of 25 samples tested were contaminated with AFB1 (15-25 $\mu \mathrm{g} / \mathrm{kg}$ ) (Zohri and Saber 1993). The aflatoxin contamination in some edible oils, like coconut oil, has been reported in some regions of England and Sri Lanka, respectively (Bordin et al. 2014).

In one of the shea \& orange concluding samples, and in one of each of the chamomile and rose concluding samples, no aflatoxin B1 was detected (< LOD). In another study, natural oil seeds including cocoa-butter substitutes (shea), were studied as substrates for aflatoxin production by two strains of A. parasiticus, and gave different levels of AFB1. AFB1 were found at low levels in that study, as well. (Kershaw 1982).

In the current study, a low AFB1 level was detected in the lavender, lemon \& sage and lily pilly fruit concluding samples $(2.42,1.56,4.48 \mathrm{ppb}$, respectively). In previous studies, no information about aflatoxin analysis in lavender and lilly pilly fruit was found. However, Gomori et al. tested the effect of clary

Table 2. AFB1 concentration ranges in the samples

\begin{tabular}{|lccc|} 
& \multicolumn{3}{c|}{ Number of samples } \\
& with AFB1 in the range $(\mu \mathrm{g} / \mathrm{kg})$ \\
\hline Sample matrix & $<$ LOD* & $1.0-5.0$ & $>5.0$ \\
\hline Chamomile & 1 & 1 & 3 \\
Green tea & - & - & 3 \\
Coconut & - & 2 & 1 \\
Rose & 1 & 1 & - \\
Shea \& orange & 1 & - & - \\
Lavender & - & 1 & - \\
Lemon \& sage & - & 1 & - \\
Avocado & - & - & 1 \\
Lilly pilly fruit & - & 1 & - \\
Jojoba oil & - & 1 & - \\
Cocoa butter & 1 & - & - \\
\hline Note: ${ }^{*}$ LOD: $<1.0 \mu \mathrm{g} / \mathrm{kg}$ for & AFB1, indicated by R-Biopharm test kit \\
manuals & & & \\
\hline
\end{tabular}


sage and lemon essential oil vapours on growth, aflatoxin production and sporulation of Aspergillus parasiticus. They found that clary sage essential oils showed concentration-dependent growth inhibition. Antifungal index and aflatoxin production using the weak antifungals, lemon essential oils, increased in parallel. The same trend was found using clary sage essential oil vapours up to $0.11 \mathrm{mg} / \mathrm{cm}^{3}$ concentration, while higher concentrations caused a sharp decrease in aflatoxin production. Only essential oil concentrations with strong growth and sporulation inhibitory effects were suitable to inhibit the aflatoxin production of A. parasiticus (Gomori et al. 2018). For this reason, in this study lemon \& sage essential oils may inhibit the AFB1 molecule at certain concentrations. As Dimic et al reported, the results showed that the lemon essential oil exhibited a good inhibition of growth of the tested molds at $>=1.25 \mathrm{mu} \mathrm{L} /$ $\mathrm{mL}$ in the agar medium and in the vapor atmosphere. (Dimic et al. 2015).

\section{CONCLUSION}

Cosmetics containing natural products can become contaminated with aflatoxins, and contaminated products may cause serious health problems. In this study, 20 hand cream samples containing natural extracts/oils were analysed. Of the tested samples, 35\% exceeded legal limits of AFB1. These findings confirm the existing knowledge that raw materials of the cosmetic products should be regularly and effectively controlled.

Peer-review: Externally peer-reviewed.

Conflict of Interest: The author has no conflict of interest to declare.

Financial Disclosure: The authors declared that this study has received no financial support.

\section{REFERENCES}

- Beiki T, Najafpour GD, Hosseini M (2018). Evaluation of antimicrobial and dyeing properties of walnut (Juglans regia L.) green husk extract for cosmetics. Color Technol 134: 71-81.[CrossRef]

- Biermann A, Terplan G (1980). Detection of Aflatoxin B-1 by Elisa. Arch Lebensmittelhyg 31: 51-57.

- Biermann A, Terplan G (1982). Experiences with a Micro-Elisa for the Detection of Aflatoxin-B1 in Food. Arch Lebensmittelhyg 33: 17-20.

- Boga M, Hacibekiroglu I, Kolak U (2011). Antioxidant and anticholinesterase activities of eleven edible plants. Pharm Biol 49: 290295. [CrossRef]

- Bordin K, Sawada MM, Rodrigues CED, da Fonseca CR, Oliveira CAF (2014). Incidence of Aflatoxins in Oil Seeds and Possible Transfer to Oil: A Review. Food Eng Rev 6: 20-28. [CrossRef]

- Buchbinder R, Gingold M, Cohen M, Hall S (1999). Complementary medicine use by rheumatoid arthritis patients in communitybased private rheumatology care. Arthritis Rheum 42: S272-S272.

- dal Belo SE, Gaspar LR, Campos PMBGM, Marty JP (2009). Skin Penetration of Epigallocatechin-3-Gallate and Quercetin from
Green Tea and Ginkgo biloba Extracts Vehiculated in Cosmetic Formulations. Skin Pharmacol Phys 22: 299-304. [CrossRef]

- Danier HJ, Ranfft K, Grassmann E (1994). Quantitative-Determination of Aflatoxin B-1 in Dairy-Cattle Feeds by Elisa. Agribiol Res 47: 256-265.

- Davis DA (1990). The Green Movement Comes to Cosmetics. Drug Cosmet Ind 146: 40.

- $\quad$ Dimic G, Kocic-Tanackov S, Mojovic L, Pejin J (2015). Antifungal Activity of Lemon Essential Oil, Coriander and Cinnamon Extracts on Foodborne Molds in Direct Contact and The Vapor Phase. J Food Process Preserv 39: 1778-1787. [CrossRef]

- Draelos ZD, Thaman LA (2006). Cosmetic formulation of skin care products. Taylor \& Francis $1^{\text {st }}$ Edition, ISBN 9780849339684.

- $\quad$ Frauen M, Rode T, Rapp C, Steinhart H (2002). Determination of green-tea catechins in cosmetic formulations and in in vitro skin extracts by high-performance liquid chromatography coupled with electrospray ionization mass spectrometry. Chromatographia 55: 43-48. [CrossRef]

- Gianeti MD, Mercurio DG, Campos PMBGM (2013). The use of green tea extract in cosmetic formulations: not only an antioxidant active ingredient. Dermato/ Ther 26: 267-271. [CrossRef] Gnonlonfin GJB, Hell K, Adjovi Y (2013). A review on aflatoxin contamination and its implications in the developing world: A sub-Saharan African perspective. Crit Rev Food SciNutr 53:349-365. [CrossRef]

- Gomori C, Nacsa-Farkas E, Kerekes EB, et al. (2018). Effect of essential oil vapours on aflatoxin production of Aspergillus parasiticus. World Mycotoxin J 11: 579-588. [CrossRef]

- Groopman JD, Kensler TW (1999). The light at the end of the tunnel for chemical-specific biomarkers: daylight or headlight? Carcinogenesis 20: 1-11. [CrossRef]

- Hacibekiroglu I, Kolak U (2013). Aflatoxins in various food from Istanbul, Turkey. Food Addit Contam B 6: 260-264. [CrossRef] Kershaw SJ (1982). Occurrence of Aflatoxins in Oilseeds Providing Cocoa-Butter Substitutes. Appl Environ Microb 43: 1210-1212.

- Mahoney N, Molyneux RJ (1998). Contamination of tree nuts by aflatoxigenic fungi: Aflatoxin content of closed-shell pistachios. J Agr Food Chem 46: 1906-1909. [CrossRef]

- Marks A (1997). Herbal extracts in cosmetics. Agro Food Ind Hi Tec 8: 28-31.

- R-Biopharm G (2006). Enzyme immunoassay for the quantitative analysis of aflatoxin B1. vol Art. No. R 1211, Darmstadt, Germany Stroka J, Petz M, Joerissen U, Anklam E (1999). Investigation of various extractants for the analysis of aflatoxin B-1 in different food and feed matrices. Food Addit Contam 16: 331-338 [CrossRef] Trucksess MW, Scott PM (2008). Mycotoxins in botanicals and dried fruits: A review. Food Addit Contam 25: 181-192. [CrossRef] Voss W (2007). Herbal ingredients in cosmetics from a clinical and toxicological point of view. Allergologie 30: 447-447. [CrossRef] Wagemaker TAL, Fernandes AS, Rosado C, Rijo P, Campos PM, Rodrigues LM (2013). Safety of green coffee oil in cosmetic formulations: From in vitro to clinical studies. Toxicol Lett 221: S231-S231. [CrossRef] Wilson DM, Mubatanhema W, Jurjevic Z (2002). Biology and ecology of mycotoxigenic Aspergillus species as related to economic and health concerns Mycotoxins and Food Safety. Springer, $p$ 3-17. [CrossRef]

- Zohri AA, Saber SM (1993). Filamentous Fungi and Mycotoxin Detected in Coconut. Zb/ Mikrobio/ 148: 325-332. [CrossRef] 